\title{
Crane Cabins Development - Are there Innovations Needed?
}

\author{
Vesna Spasojevic Brkić ${ }^{1}$, Zorica Veljković ${ }^{1}$, Aleksandar Brkić \\ ${ }^{1}$ University of Belgrade, Faculty of Mechanical Engineering, Industrial Engineering Department, Kraljice Marije 16, Belgrade, Serbia \\ 2 Innovation Center, Faculty of Mechanical Engineering, Kraljice Marije 16, Belgrade, Serbia
}

\begin{abstract}
The use of load lifting/handling equipment makes workplaces dangerous given the high potential for injury, loss of life and material damage. Cranes are extremely important component in many different industrial operations today. Previous researches have highlighted the need of such equipment to be safely operated and easily maintained, while associated human errors should be considerably reduced. Hence, human centered issues have to be analyzed first and according to those conclusions certain innovations are necessary. This survey offers new crane cabin design based on univariate and multivariate approaches applied on operators' anthropometric data in aim to enable their ergonomic convenience. Later, design issues are solved, through static and dynamic calculations using finite method elements in that context. Finally, crane cabin design in the light of Industry 4.0 concept is further analyzed together with inventions that are helpful there. Accordingly, we can conclude that in crane cabins development process proposed innovations are needed and very beneficial.
\end{abstract}

\section{Introduction}

The use of load lifting/handling equipment makes workplaces dangerous given the high potential for injury, loss of life and material damage. Cranes are extremely important component in many different industrial operations and are involved in a large number of injuries, deaths or damages [1], [2], [3], [4]. In fact, estimates suggest that cranes contribute to as many as one-third of all fatalities associated with on-site operations [5]. Beavers et al. [6] give an example that crane is one of the major causal factors of fatalities in the construction industry. Also, in Netherlands, crane activities are responsible for $4 \%$ of the reported accidents [7]. Raviv et. al. [8] have studied near misses related to crane work and their safety risk potential and discussed their very huge potential for escalating into accidents. Also, previous research demonstrated that $42 \%$ of all accidents are linked to the crane cabin design [9].

It is evident that contemporary procedures in the development process of crane cabins are still based on the specific experience of the manufacturers and historical guidelines that still very often are arbitrary and subjective. Accordingly, it is not surprising that previous researches have highlighted the need of such equipment to be safely operated and easily maintained, while associated human errors have to be considerably reduced [10]. Hence, special attention has to be given to the crane-operator's workplace, including its' redesign, with main aims both to come closer to Industry 4.0 concept (I4.0) and prevent occupational injuries, illnesses, fatalities and undesired exposures.
There is the explicit need for more objective, theoretically justified and consistent models in crane cabins development process. Accordingly, we expect that answer on question if there are innovations needed in crane cabins development process is positive. This paper is going to propose and justify innovations that are needed in this field.

The structure of our paper is as follows. Since according to Spasojevic Brkic et al. [11], Swuste [12] and Milazzo et al. [10] scenarios such as 'crane instability, 'jib instability' and 'hoisting equipment instability' today contribute less than human centered problems to accidents today, human centered issues have to be analyzed and according to those conclusion certain innovations should be proposed. Later, design issues should be discussed in that context. Finally, crane cabin design in the light of Industry 4.0 concept should be further analyzed together with inventions that are helpful there. Conclusion is the last part of this paper that circumscribes the discussed issues.

\section{Human centered issues in crane cabins design}

Operating a crane demands a static sedentary position with hands held steady on the operating handles with frequent twisting, deep sideways bandings and exposure to whole-body vibration as risk factors [13]. Kittusamy \& Buchholz [14] add that awkward posture during the operation is a consequence of improper cab design and work procedures, emphasizing that poor visibility of the task, limited room in the cab, excessive force required to 
operate levers/pedals, and improper seat designs are some of the characteristics of a poorly designed cab. Our survey done on 17 types of crane cabins located in Serbia and manufactured by 6 different domestic and international producers [15] shows that users are not satisfied with current cabins design, as can be seen on Fig. 1 (index of their average un-satisfaction ranges from 1.6 to 4.9 on scale $1-5)$.

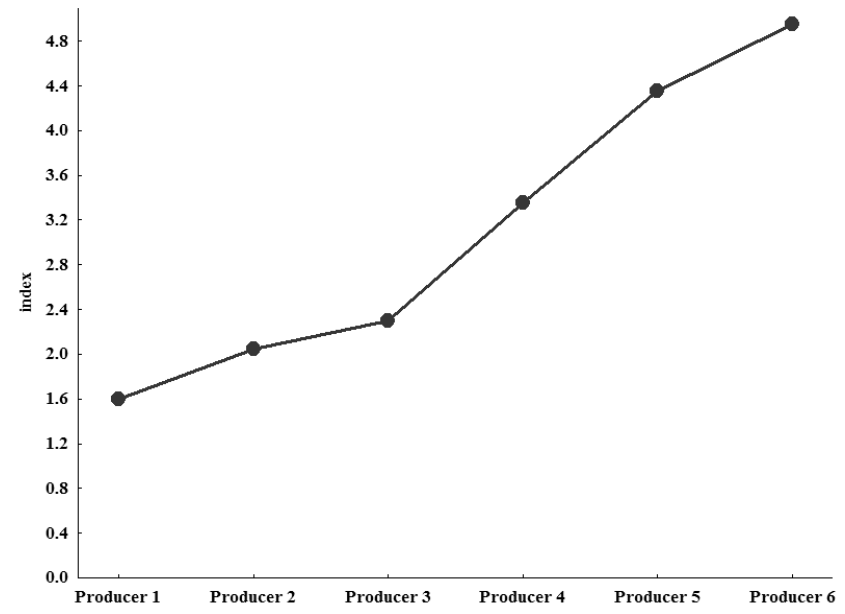

Figure 1. Crane operators index of un-satisfaction with current crane cabins designs

Our survey [15] also shows that operators most frequently complain on the following crane cabins problems. The highest inconvenience cause armrests and inappropriately designed seat together with not sufficient upward visibility and obstructed view of the operation. It indicates the need to conduct further ergonomic analyses from the aspect of the anthropometric measurements with appropriate modeling approach applied.

To facilitate improved crane cabin design anthropometric dimensions of 83 crane operators in the sample were collected in Serbia. Methodology applied covered both multivariate and univariate anthropometric modeling.

The percentiles approach, as one of the most frequently used univariate approach [16], usually accommodates persons from the 5th to 95th percentile with aim to fit the $90 \%$ of the population of interest. Practical problem with this approach lies in the fact that percentiles are not additive and a model based on more than one dimension includes less than the intended population proportion. Also, percentile method includes only overall large and small individuals, disregarding individuals with different body configurations, which are often critical dimensions in design. Results on univariate anthropometric modeling results based on anthropometric measures of 83 Serbian crane operators are explained in detail in [15] and shown in Figures 2 and 3. Certain authors such as Pheasant and Haslegrave [17] argue that percentiles approach is neither realistic nor proportioned properly for good-fitting designs and propose application of multivariate approaches. Accordingly, in that aim we propose multivariate modeling such as one described in detail in Essdai et al. [18] and shown in Figures 4 and 5.

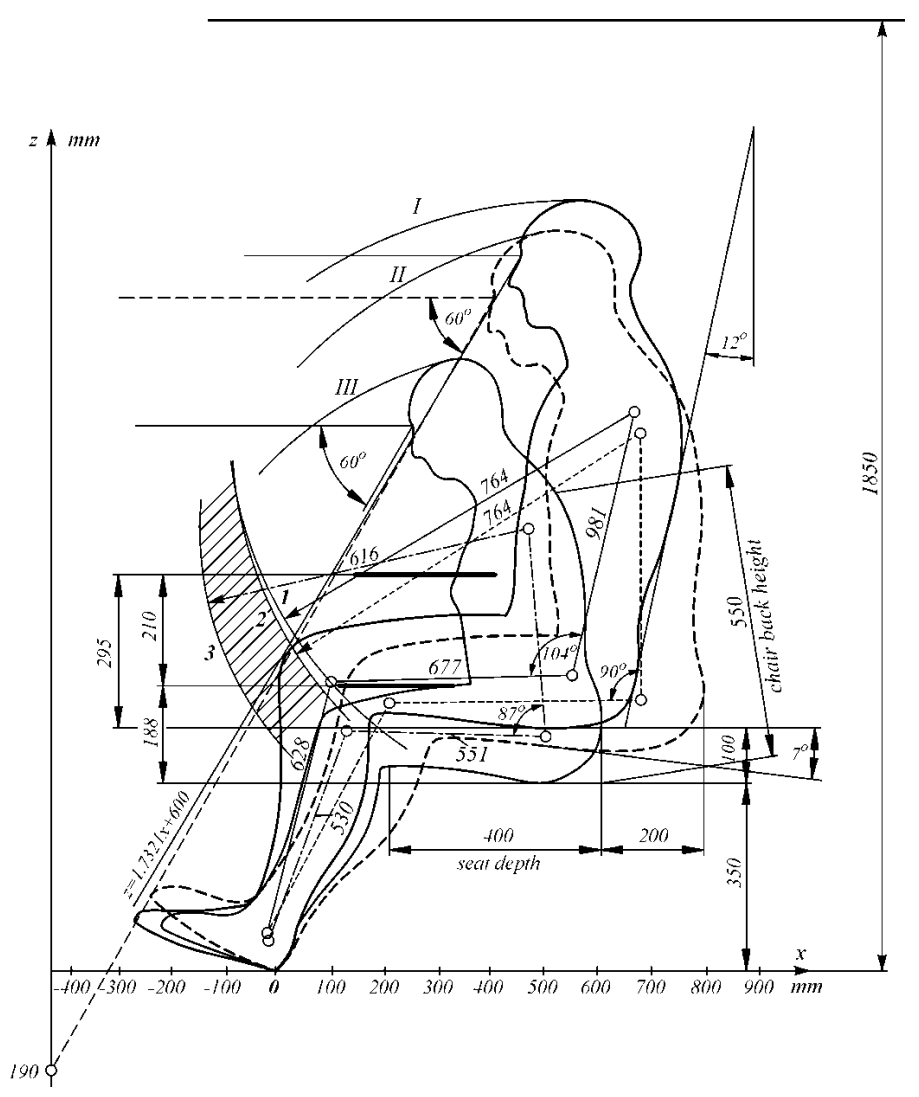

Figure 2. The space necessary for the placement of the crane operator in the cabin, in the $z-x$ plane, when using univariate percentile approach [15]

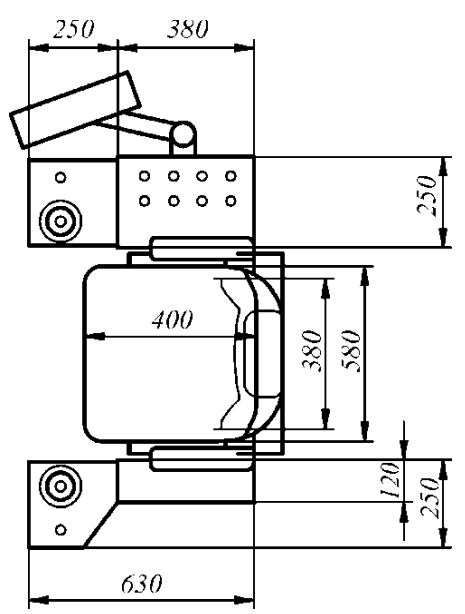

Figure 3. The space necessary for the seating of the crane operator in the cabin, in the $\mathrm{x}-\mathrm{y}$ plane, when using univariate percentile approach [15]

\section{Finite element method calculations in innovative crane cabin design}

Using proposed interior space and finite element method and KOMPIS software (Computer Modeling and Structures Design Software) innovative cabin where 
operators should feel better was designed. Geometry of the numerical model of the cabin with the number of nodes and beam finite elements is shown in Figures 6 and 7. It can be seen that the model has 65 nodes and 111 finite elements of the beam type, as shown in figure 6 , which describe basis for static calculation as given in [19] The cab construction has the following sizes: glass area $8.2 \mathrm{~m} 2$, steel S325J2G3 $469 \mathrm{~kg}$ and operator with chair $150 \mathrm{~kg}$. Static calculations show that deformation is extremely small, that the maximum strain is extremely low and that the rigidity of the cabin construction is extremely high.

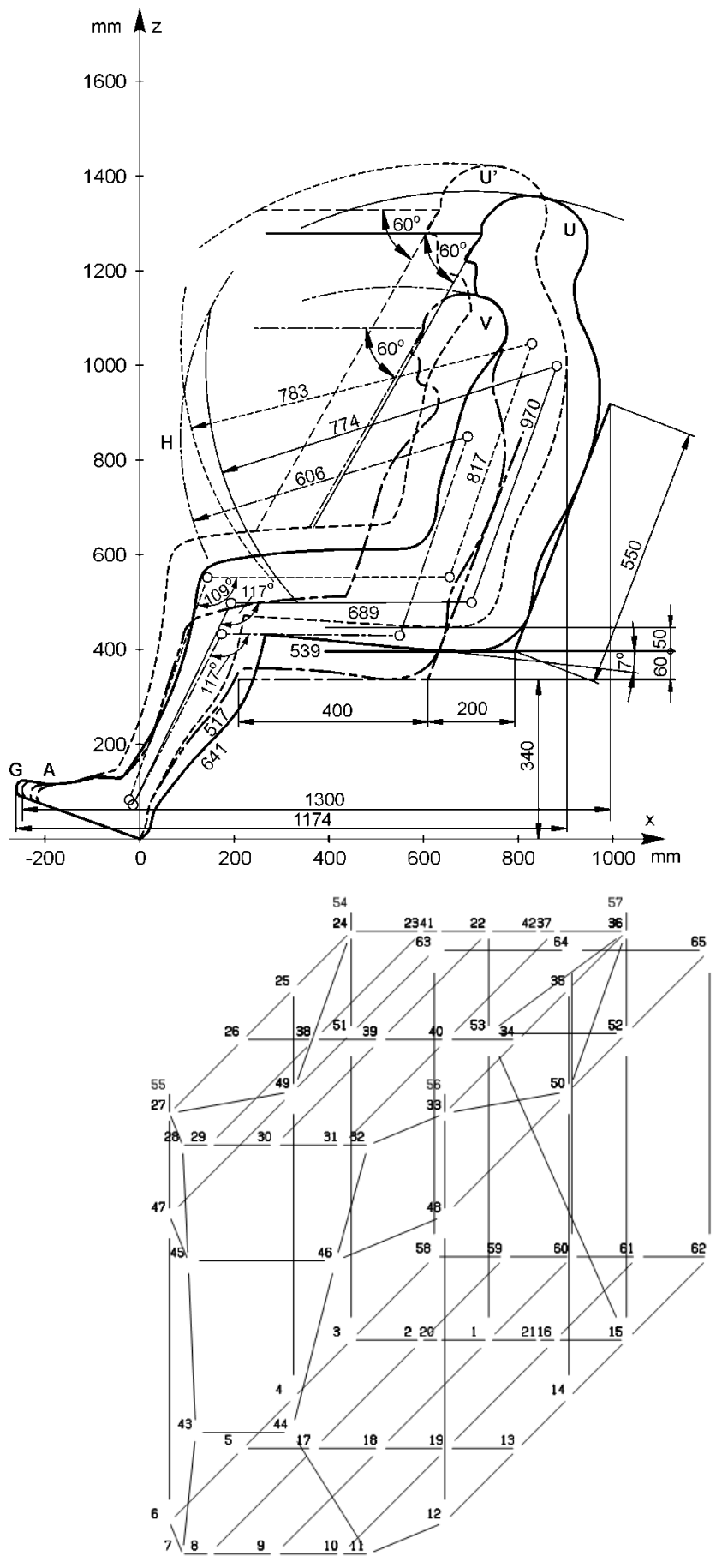

(a)
Figure 4. Space required for accommodation of crane operator in the cabin, in $x-z$ plane when using multivariate approach [18]

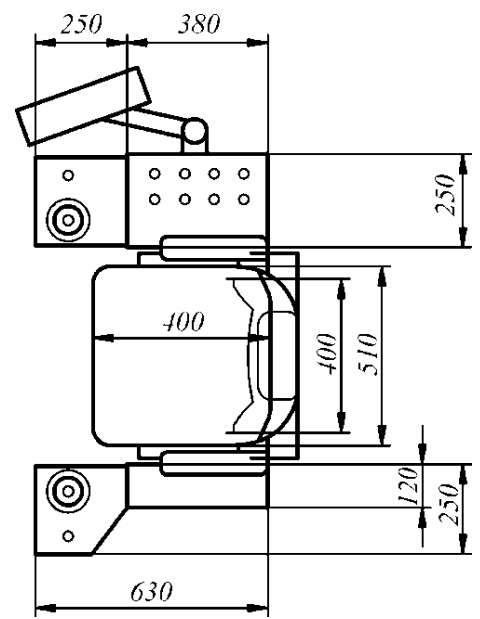

Figure 5. Space required for accommodation of crane operator in the cabin, in $x-y$ plane when using multivariate approach [18]

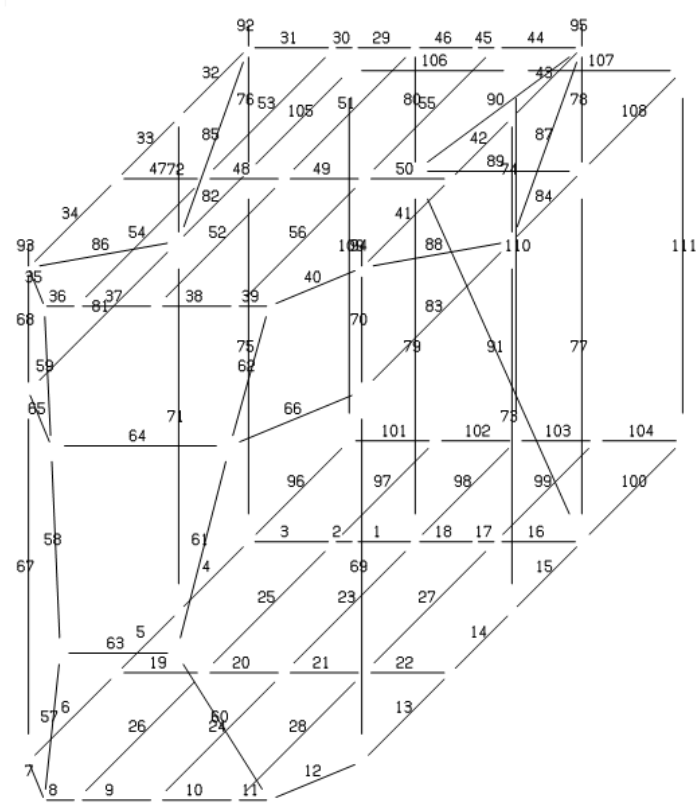

(b)

Figure 6. Node numbers (a) and beam type finite elements (b) in cabin structure geometry model [19] 

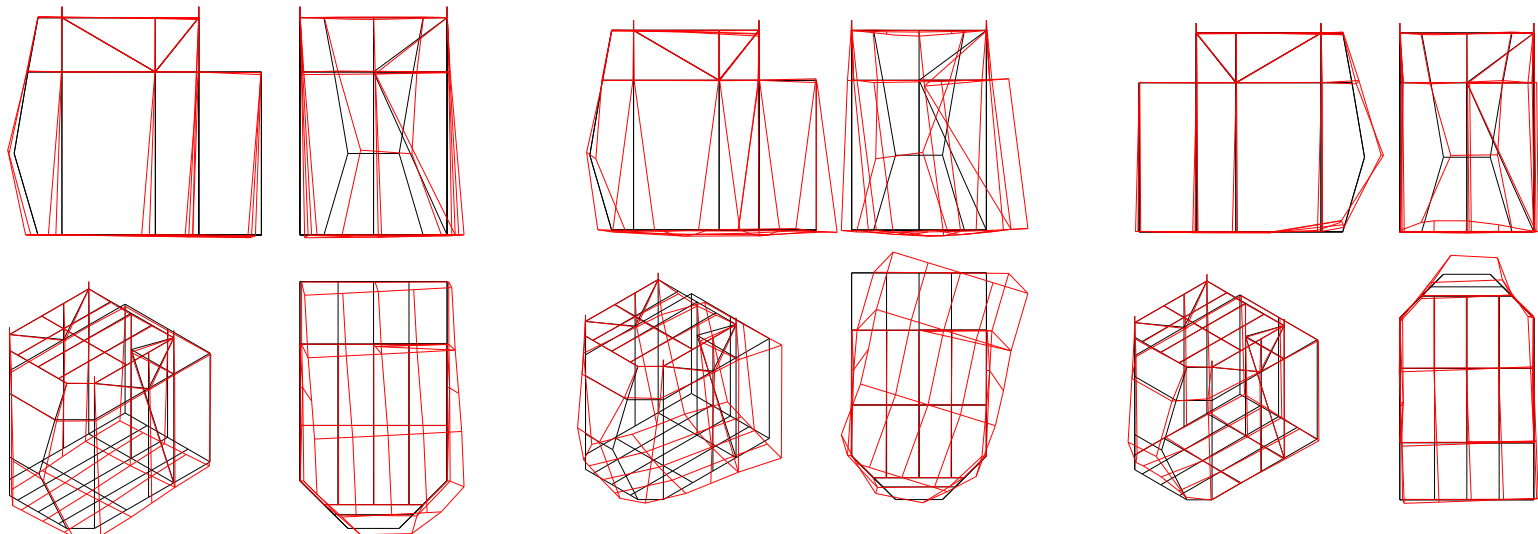

Figure 7. Crane cabins' modes of oscillation (the first, the third and the sixth mode of oscillation).
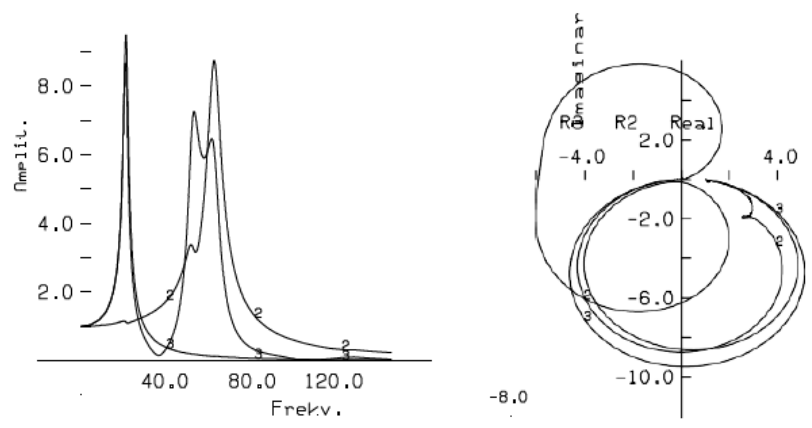

Figure 9. Dynamic response of the cabin due to vertical exciting of the crane structure
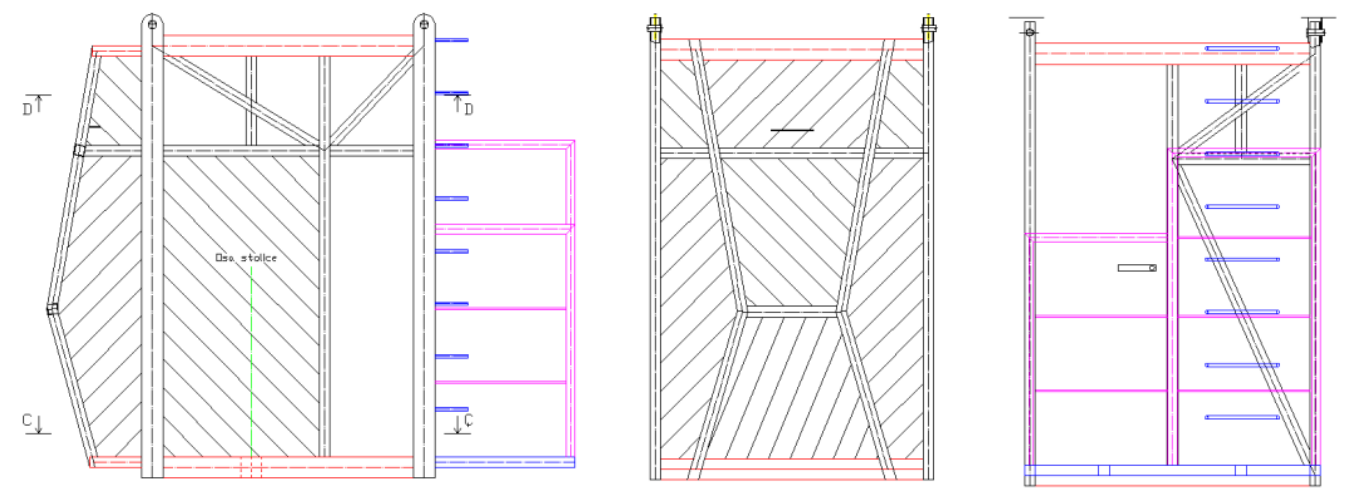

Figure 10. Technical drawings of the crane cabin prototype

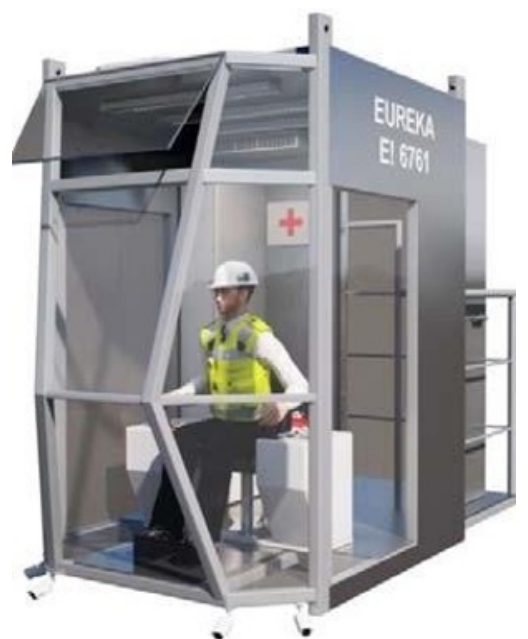

(a)

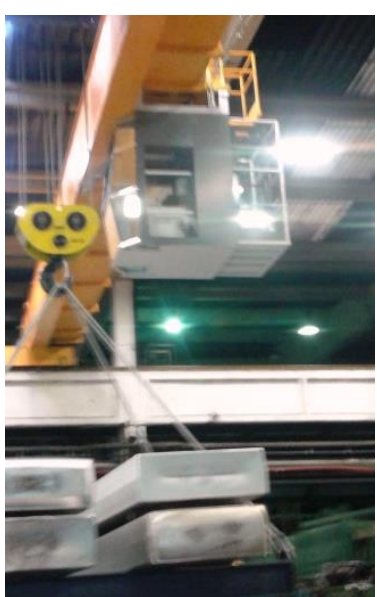

(b)

Figure 11. New crane cabin prototype model (a) and produced cabin settled in one of Serbian factories (b) 
Dynamic calculation of crane cabin structure elements included Eigen-frequencies and main oscillation modes and forced damped oscillation within the frequency range, as shown in Fig. 7. It can be noticed that own frequencies are extremely high and that a dynamic response to a possible crane initiative is favorable.

Fig. 8 shows dynamic response of cabin structure at the seat location due to vertical excitation within the frequency domain, while Fig. 9 gives technical drawings on innovative cabin. Fig. 10 presents technical drawings of the cabin, while Fig. 11 shows the cabin prototype cabin settled in one of Serbian factories.

The innovative cabin structure completely met the requirements since the static and dynamic stiffness of the cabin construction is extremely favorable. Hence, it is possible to conclude that it is possible to replace the selected material of the cab structure (S325J2G3) with the alloy of aluminum. New crane cabin represents sustainable product with less resource usage due to decrease of cabin mass and increase of adaptability to human and today it works successfully in one of Serbian factories.

\section{Crane cabin design in the light of Industry 4.0 concept}

Crane operators visibility problems have to be solved, too [20], [21]. In recent years, many innovative systems aimed at exploiting the potentials of "smart" technologies for the industrial and occupational safety are appearing [22]. In that aim innovative Visual Guidance System (VGS) is proposed, too (in detail in [15]). VGS represents the software that solves the problem of limited vision in moving loads within complex sites, which can be the cause of collisions between the load and obstacles and/or intrusions in the workspace and provides the operator with a safe guide in carrying out his/her tasks. It makes use of stereoscopic vision imaging to capture and process images of the workspace and provides useful information for crane operator.

\section{Conclusion}

According to results of this paper an answer on question if there were innovations needed in the crane cabins development process is positive. This paper has proposed innovations that are needed in the field and manner of its implementation. It has started from operators needs survey done in Serbia that has shown that they do not feel comfortable in existing cabins' design. After that, new modeling approach based on multivariate statistics is proposed and it has changed dimensions of interior space needed for operator. It is to expect that the procedure proposed herein not only eliminates anthropometrical inconsistency, but also decreases the risks of operators' musculoskeletal disorders, which further increases their job satisfaction, lowers the risk of injuries and fatalities, and, therefore, results in an overall increase of productivity and safety on site as well.Accordingly, static and dynamic calculations for innovative cabin design have been done. Based on technical drawings innovative cabin has been produced and it works with success in one of Serbian factories today. Also, herein is proposed an innovation that solves operators' visibility problems Visual Guidance System. The suggestion for further research thus refers to the modeling by using more data of crane operators` anthropometric measures from other countries to come to universally applicable innovative solution and further development of VGS.

\section{References}

1. Aneziris, O. N., Papazoglou, I. A., Mud, M. L., Damen, M., Kuiper, J., Baksteen, H., ... \& Post, J. G. (2008). Towards risk assessment for crane activities. Safety science, 46(6), 872-884.

2. Krishna, O. B., Maiti, J., Ray, P. K., Samanta, B., Mandal, S., \& Sarkar, S. (2015). Measurement and modeling of job stress of electric overhead traveling crane operators. Safety and health at work, 6(4), 279288.

3. Fang, Y., Cho, Y. K., \& Chen, J. (2016). A framework for real-time pro-active safety assistance for mobile crane lifting operations. Automation in Construction, 72, 367-379.

4. Spasojević Brkić, V. K., Veljković, Z. A., Golubović, T., Brkić, A. D., \& Kosić Šotić, I. (2016). Workspace design for crane cabins applying a combined traditional approach and the Taguchi method for design of experiments. International Journal of Occupational Safety and Ergonomics, 22(2), 228-240.

5. Neitzel, R. L., Noah S. S., and Ren K. (2001). A review of crane safety in the construction industry. Applied Occupational and Environmental Hygiene, 16 (12), 1106-1117.

6. Beavers, J. E., et al. (2006). Crane-related fatalities in the construction industry. Journal of Construction Engineering and Management 132.9: 901-910.

7. Haynes S. and Williams K. (2008). Impact of seating posture on user comfort and typing performance for people with chronic low back pain. International Journal of Industrial Ergonomics 38, 35-46.87

8. Raviv, G., Shapira, A., \& Fishbain, B. (2017). AHPbased analysis of the risk potential of safety incidents: Case study of cranes in the construction industry. Safety Science, 91, 298-309.

9. Gambatese, J. A., Behm, M., \& Rajendran, S. (2008). Design's role in construction accident causality and prevention: Perspectives from an expert panel. Safety Science, 46 (4), 675-691.

10. Milazzo, M. F., Ancione, G., Brkic, V. S., \& Vališ, D. (2016). Investigation of crane operation safety by analysing main accident causes. Risk, Reliability and Safety: Innovating Theory and Practice: Proceedings of ESREL 2016 (Glasgow, Scotland, 25-29 September 2016), 74.

11. Spasojević-Brkić, V., Milazzo, F. M., Brkić, A. \& Maneski, T. (2015). Emerging risks in smart process industry cranes survey: SAF€ RA research project SPRINCE. Serbian Journal of Management, 10(2), 247-254. 
12. Swuste, P. (2007). Qualitative methods for occupational risk prevention strategies in safety, or control bandingSafety. Safety Science Monitor, 11, 1-7.

13. Burdorf, A., \& Zondervan, H. (1990). An epidemiological study of low-back pain in crane operators. Ergonomics, 33(8), 981-987.

14. Kittusamy, N.K., \& Buchholz B. (2004). Whole body vibration and postural stress among operators of construction equipment: A literature review. J. Saf. Res. $35: 255-261$

15. Spasojević Brkić, V. S., Klarin, M. M., \& Brkić, A. D. (2015). Ergonomic design of crane cabin interior: The path to improved safety. Safety science, 73, 43-51.

16. Zunjic, A., Brkic, V. S., Klarin, M., Brkic, A., \& Krstic, D. (2015). Anthropometric assessment of crane cabins and recommendations for design: A case study. Work, 52(1), 185-194.

17. Pheasant S., Haslegrave C.M. (2016) Bodyspace: Anthropometry, ergonomics and the design of work. CRC Press.
18. Essdai, A., Spasojević Brkić, V. K., Golubović, T., Brkić, A., \& Popović, V. (2018). Crane cabins' interior space multivariate anthropometric modeling. Work, 59(4), 557-570.

19. Brkić, A., Maneski, T., Brkić, V. S., \& Golubović, T. (2015). Industrial Safety Improvement of Crane Cabins. Structural Integrity and Life, 15 (2), 95-102.

20. Fang, Y., Teizer, J., \& Marks, E. (2014). A framework for developing an as-built virtual environment to advance training of crane operators. In Construction Research Congress 2014: Construction in a Global Network (pp. 31-40).

21. Ansaldi, S. M., Agnello, P., \& Bragatto, P. A. (2018). Smart Safety Systems: Are They Ready To Control The Hazard Of Major Accidents?. WIT Transactions on The Built Environment, 174, 169-180. 